\title{
Modulation of the Mu and Kappa Opioid Axis for the Treatment of Chronic Pruritus
}

\author{
Sarina Elmariah, MD, PhD', Sarah Chisolm, MD², Thomas Sciascia, MD², Shawn G. Kwatra, MD4
}

'Massachusetts General Hospital, Boston, MA, USA; 'Emory University Department of Dermatology, Atlanta, GA, USA; VA VISN 7, USA; 3 Trevi Therapeutics, New Haven, CT, USA; JJohns Hopkins University School of Medicine, Baltimore, MD, USA

\section{Introduction}

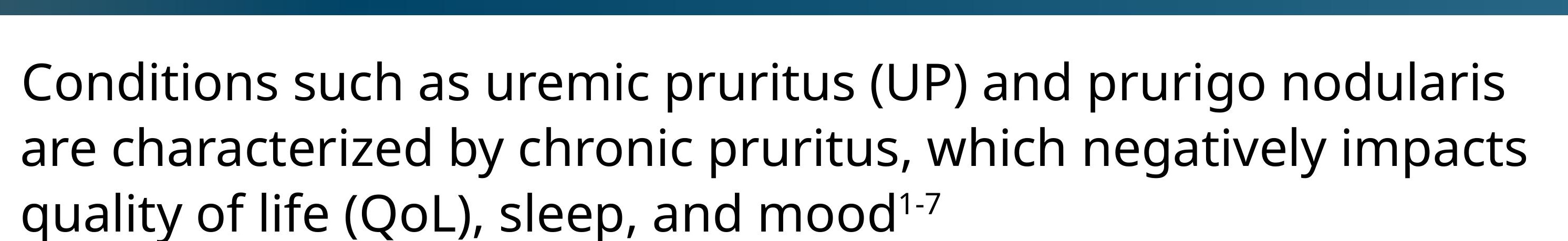

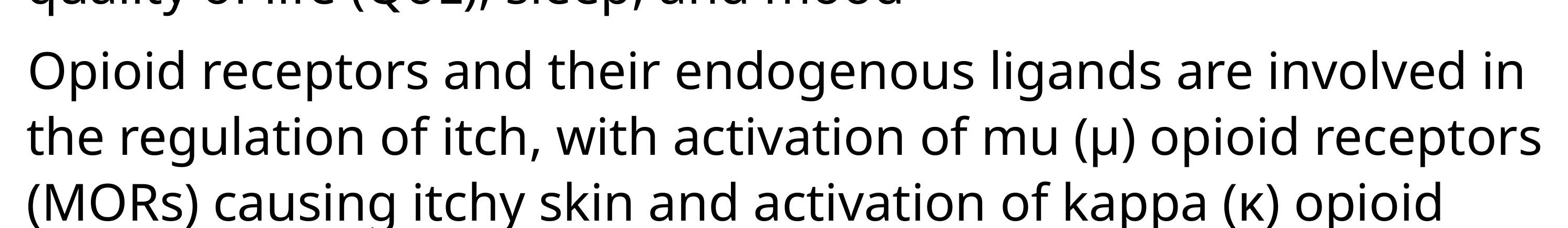

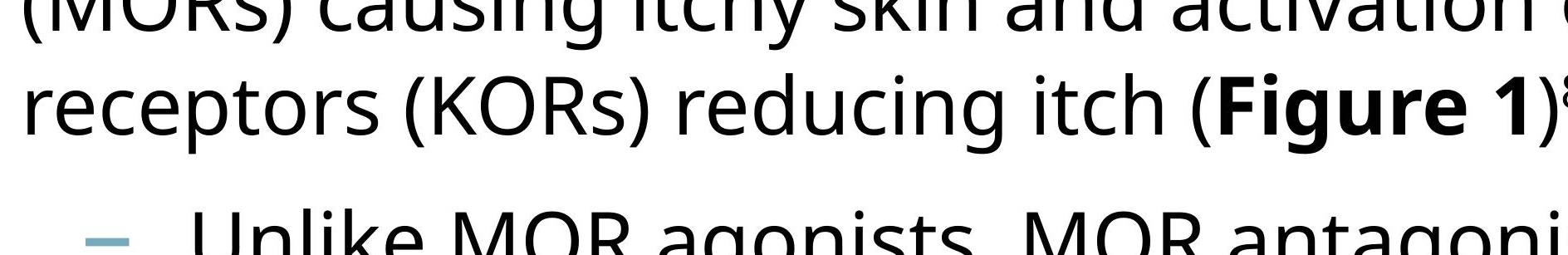

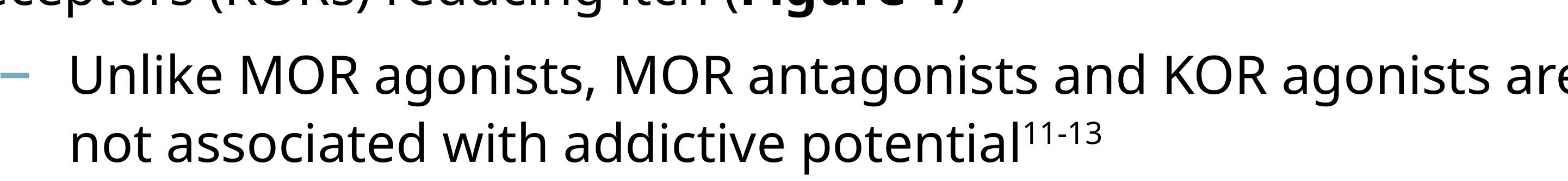

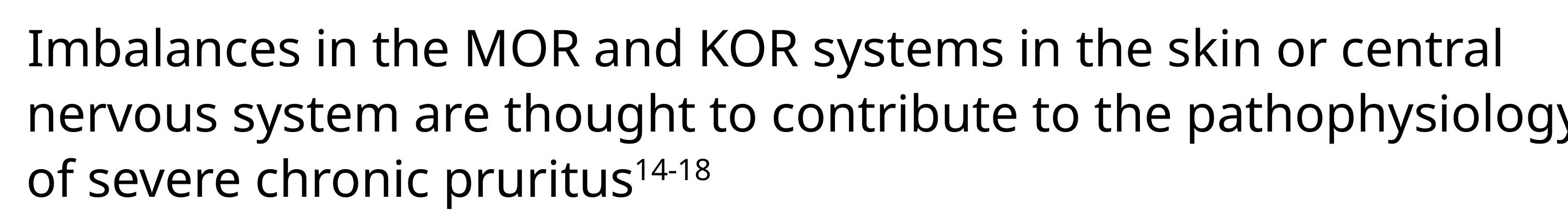
Accerdingly, trageteng Mors and Kork represents an active area

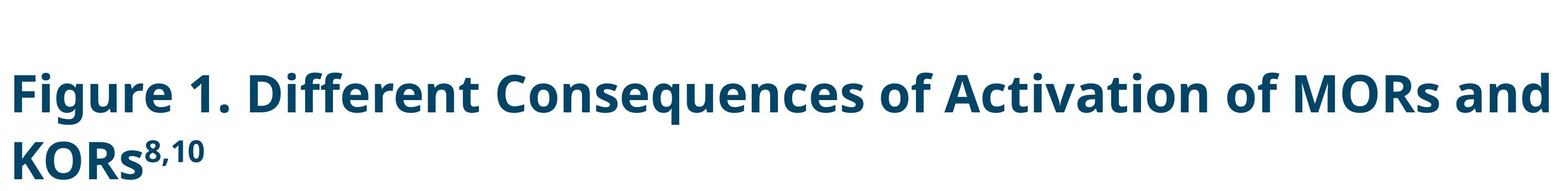

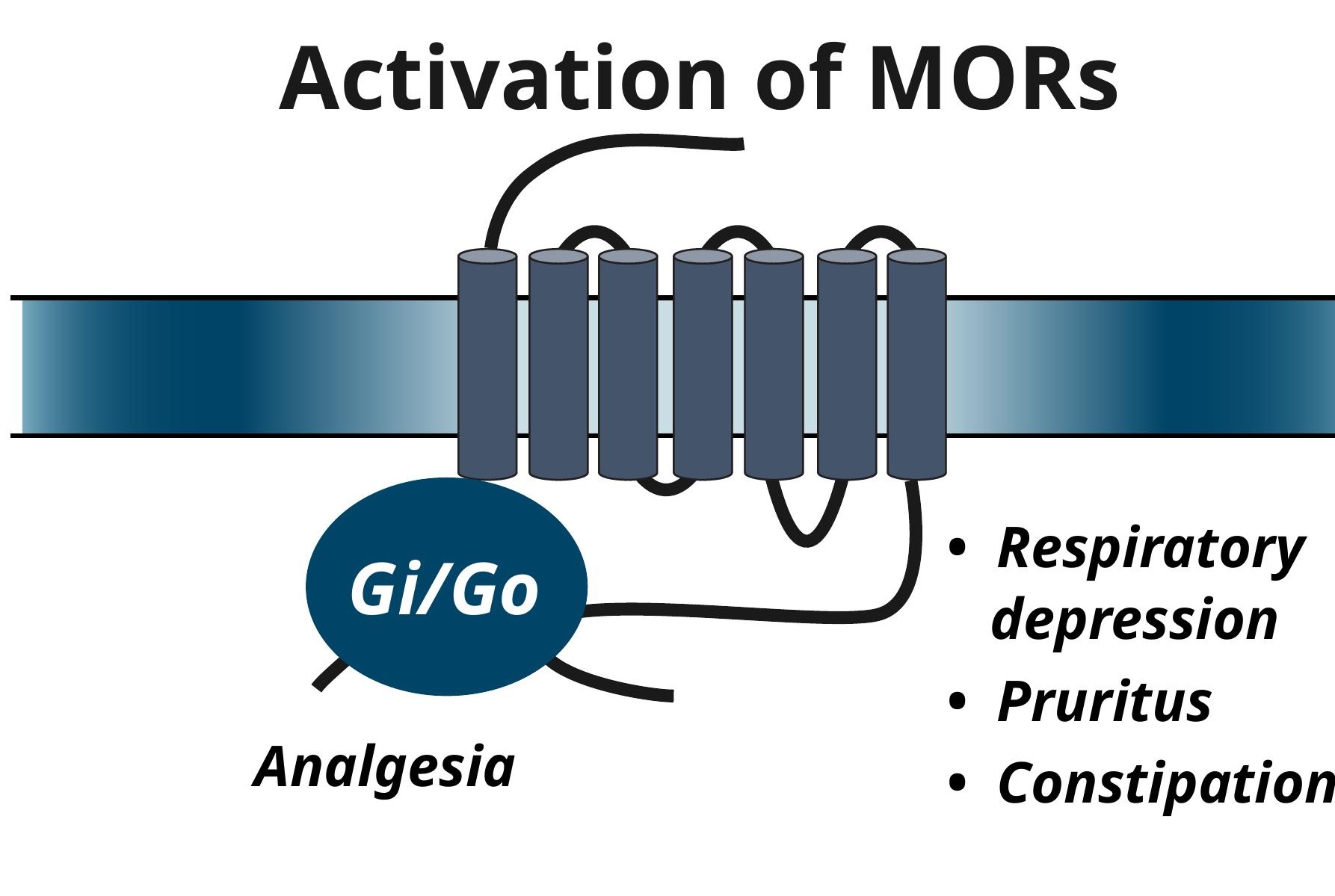
Activation of KORs

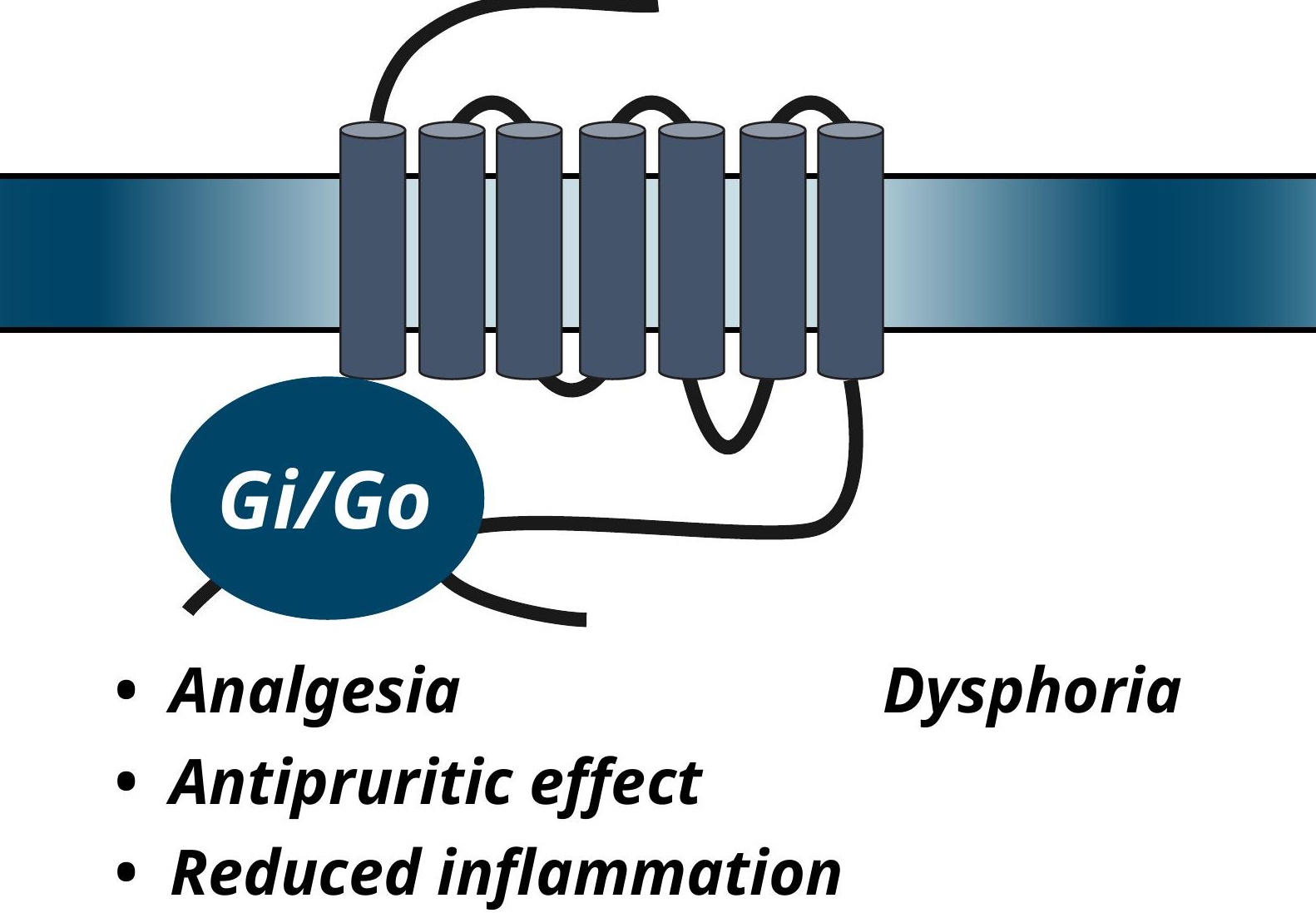

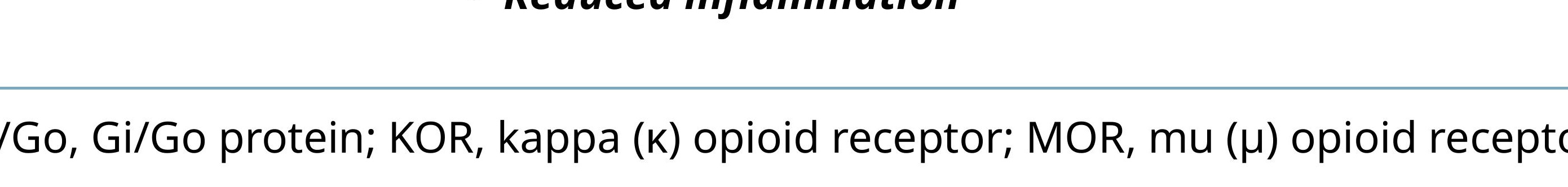

Objective

To provide a narrative overview of studies supporting opioid
receptor agonists and/or antagonists in chronic pruritus

\section{Methods}

The PubMed database was searched to identify English-
language literature no the role of opioid receptor agonists and/or

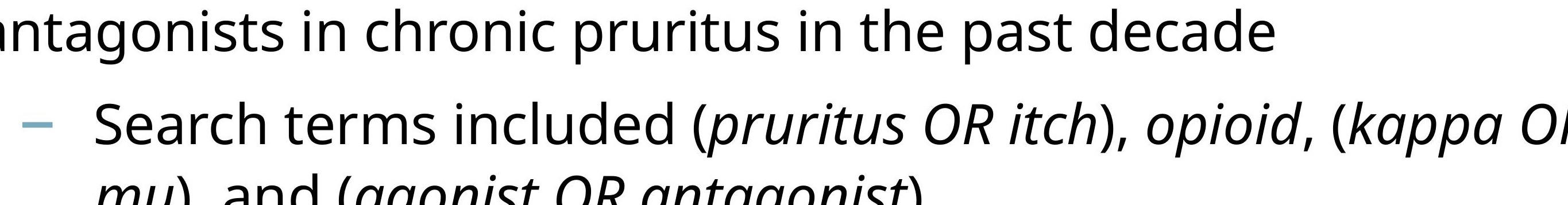
- Select references cited within identified publications were Findings from rele
narrative review

\section{Results}

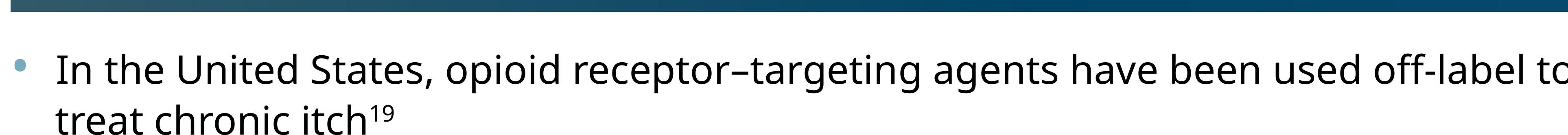

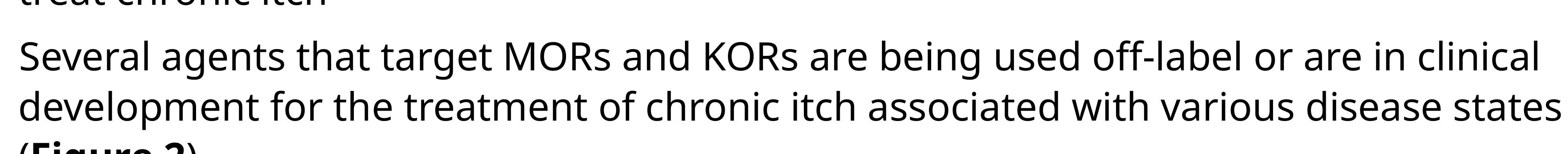
(igure 2

Figure 2. Agents Targeting Mops and Konsulcos

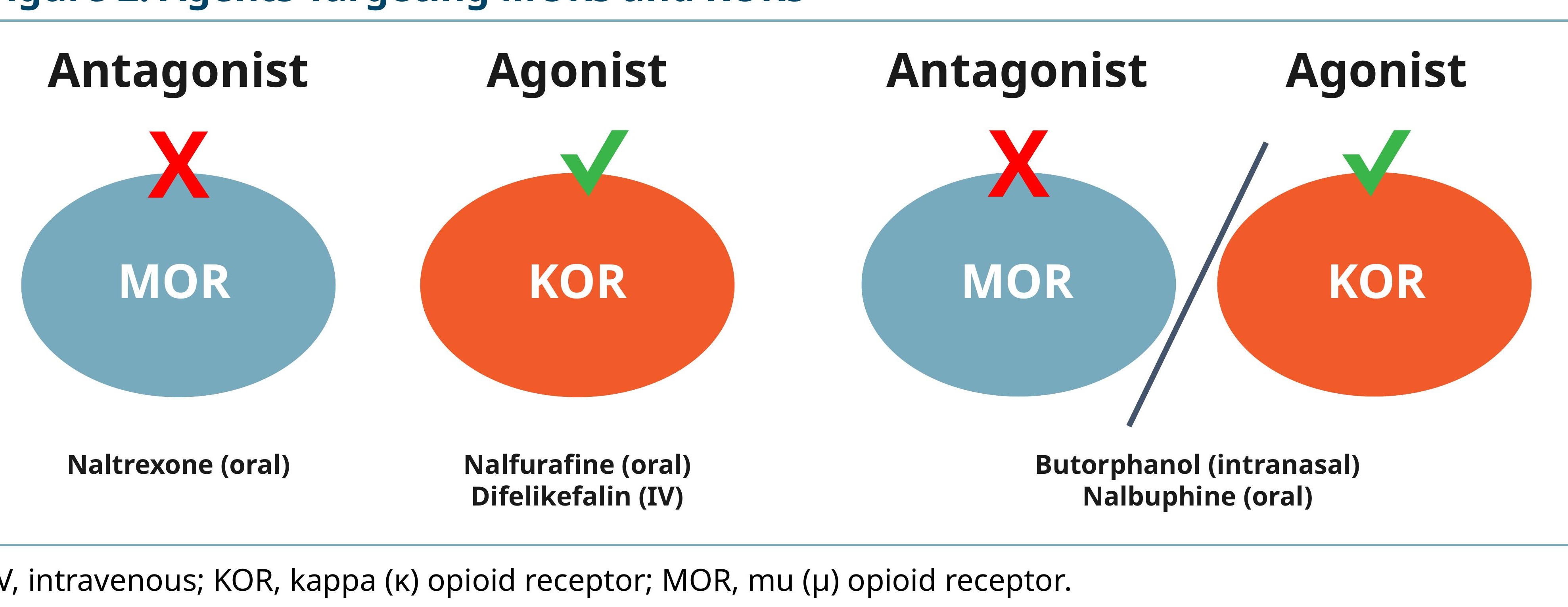

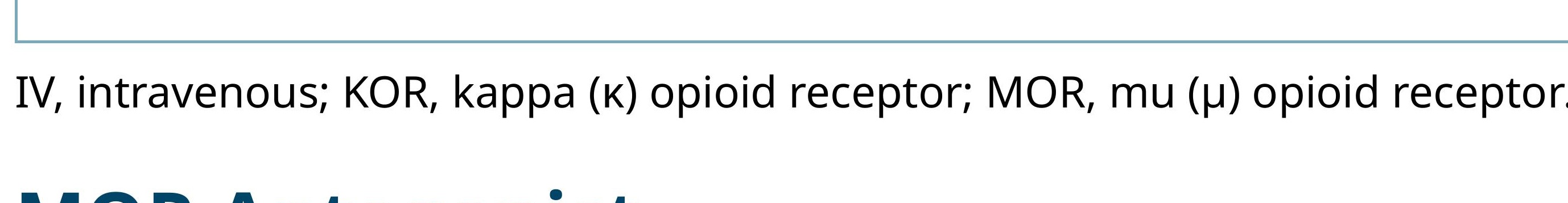

MOR Antagonist

Naltrexone
- An observational study (N=18) of the MOR antagonist naltrexone $(50 \mathrm{mg} / \mathrm{d})$, used
off nodibul for the treatment of severe itch of varying etiologies, including prurigo
nodulis,
ifigure $33^{20}$

16 patients (88.9\%) experienced symptomatici improvement
5 patients (287.98) reported adverse events (AEs), including insomnia, fatigue,
constipation, and anorexia

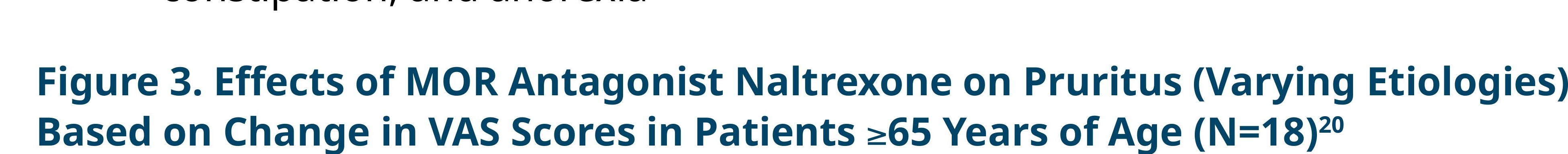

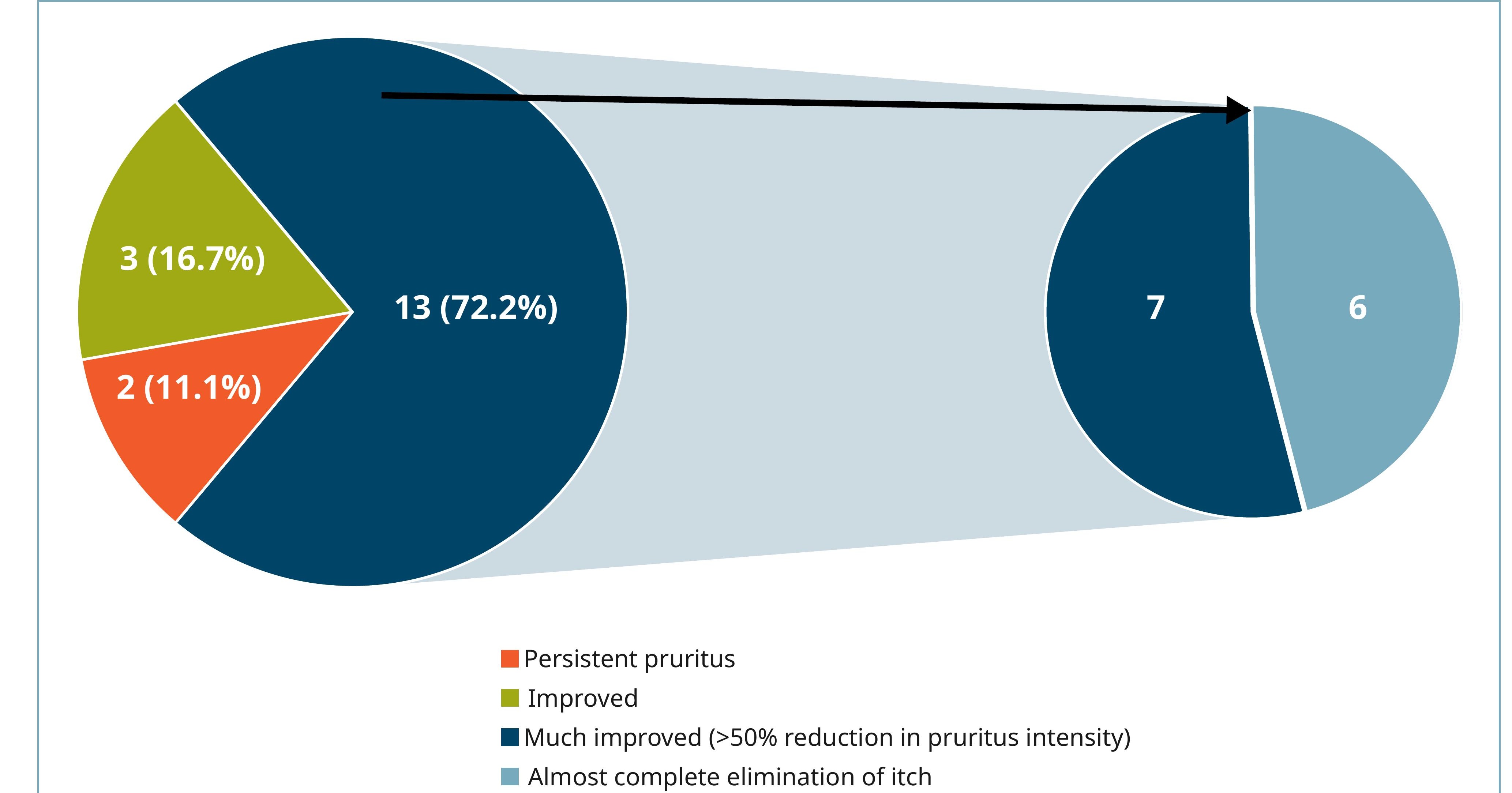

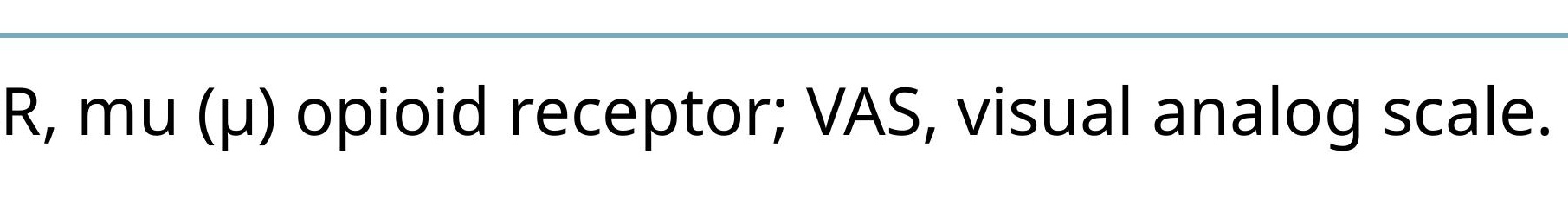

KOR Agonists

Nalfuraffine
- Nafurafine is a KOR agonist approved in Japan for the treatment of UP³

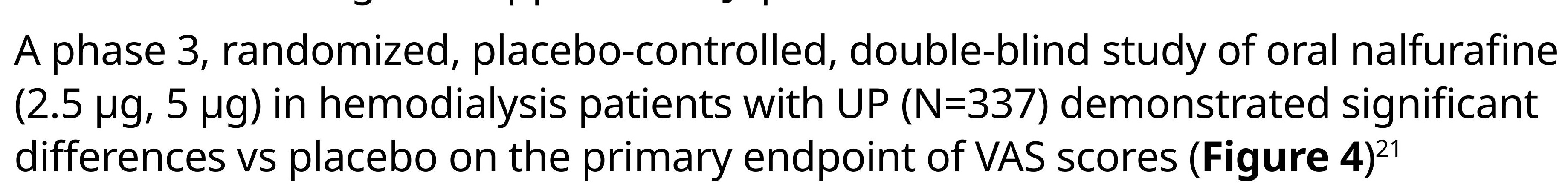
- The most frequent AE was insomnia

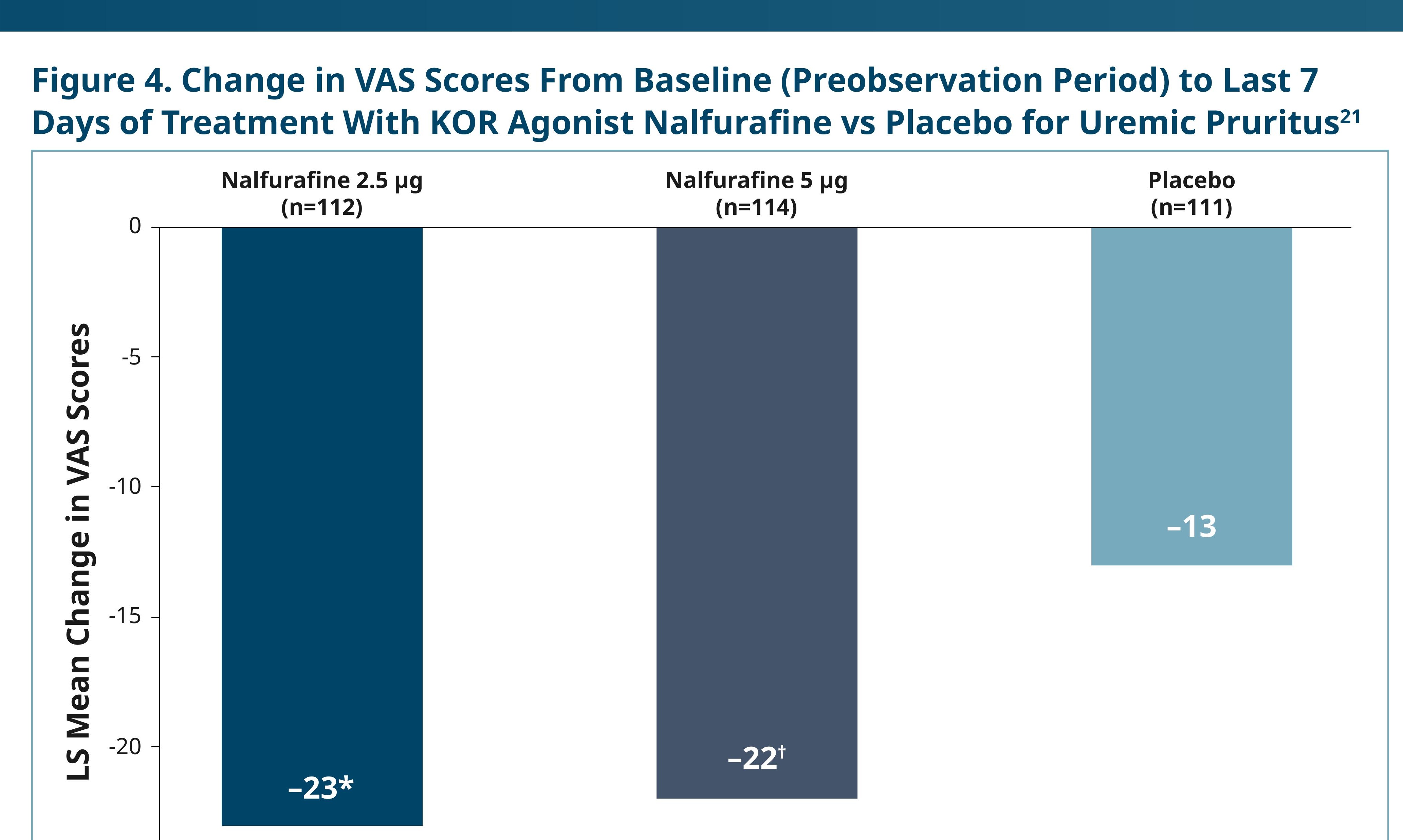

KOR, kappo (k) opioid recestor L, L, least squares; VAs, visual analog scede

Difelikefalin

- Two randomized, double-blind, placeebo-controlled trials evaluated the peripherally
acting KOR agonist diffelikefaldin in hemodialysis patients with moderate-to-severe

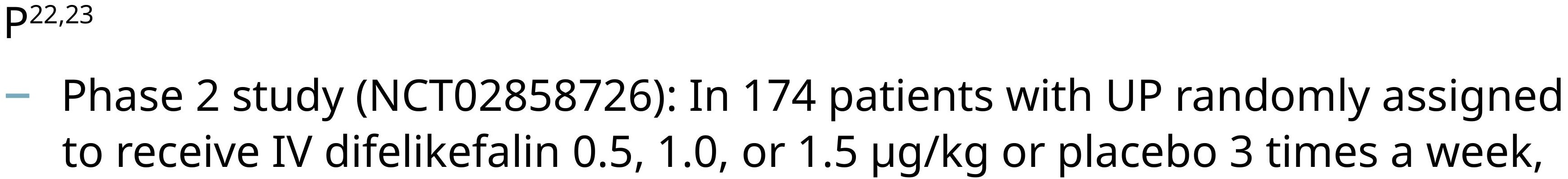

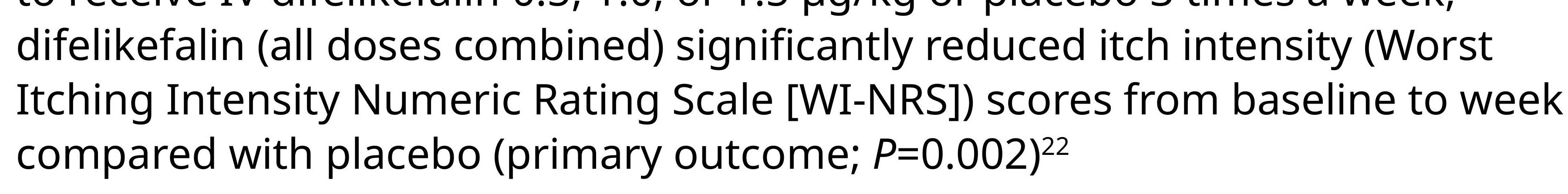
Aase 3 study (NCT03422653): Compared with placebo, a significantly greater

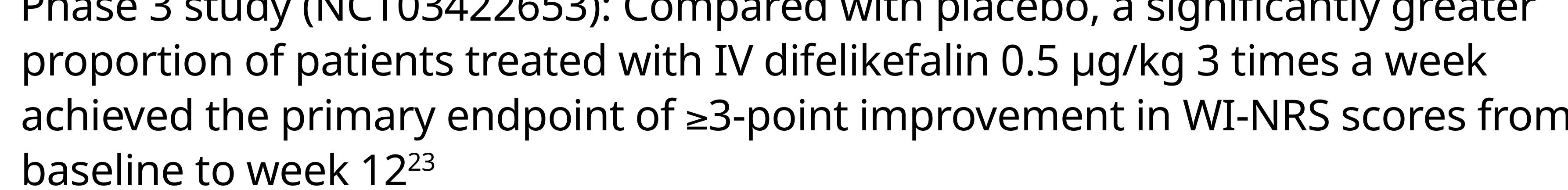
Itch-related Qol was improved in both trials, and the most common AEs were
diarrhea, dizziness, and nausealvomiting, with most being mild or moderate Combination MOR Antagonists/KOR Agonists

Butorphanol

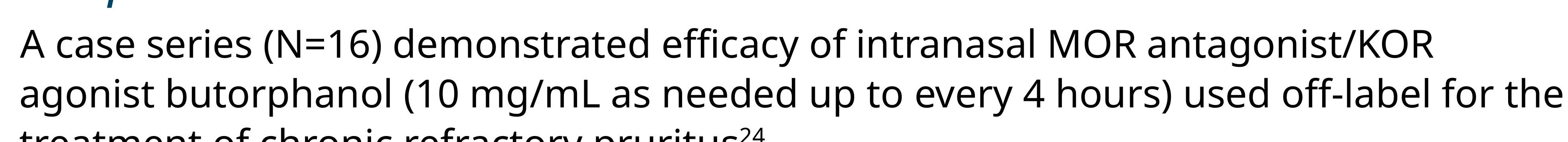

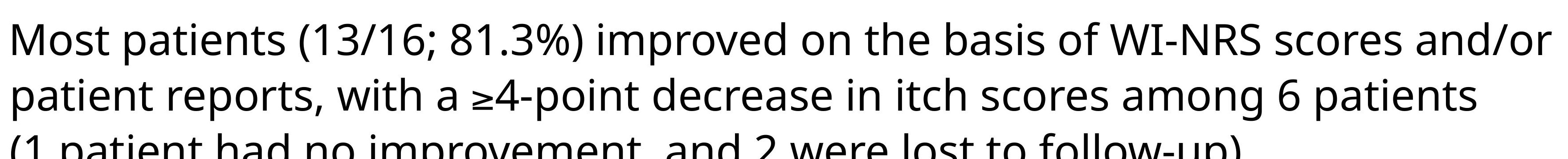

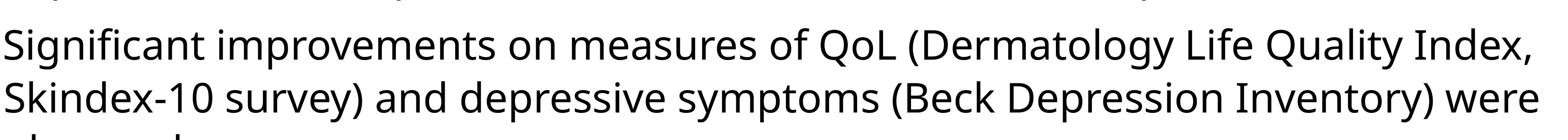
sindex-10 survey and depressive symploms (Bech Depression
observed albuphin

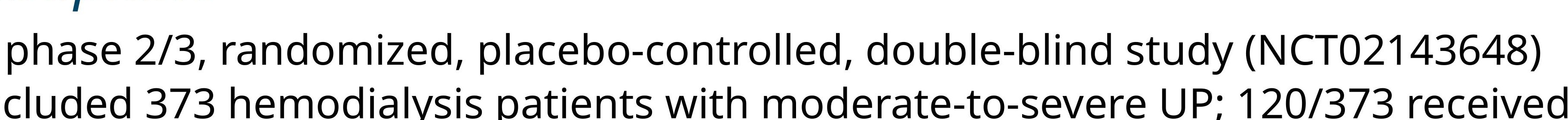
the oral MOR antagonistrtKoR agonist nalbuphine (NAL) $120 \mathrm{mg}$ (doses based on

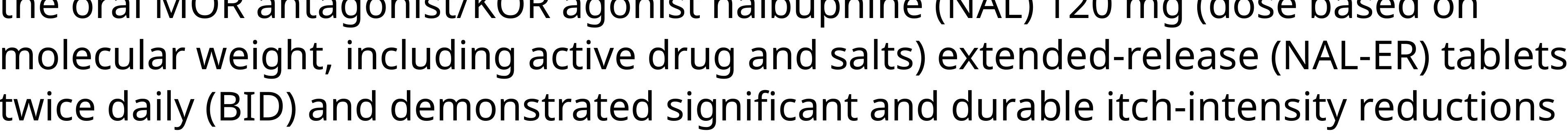

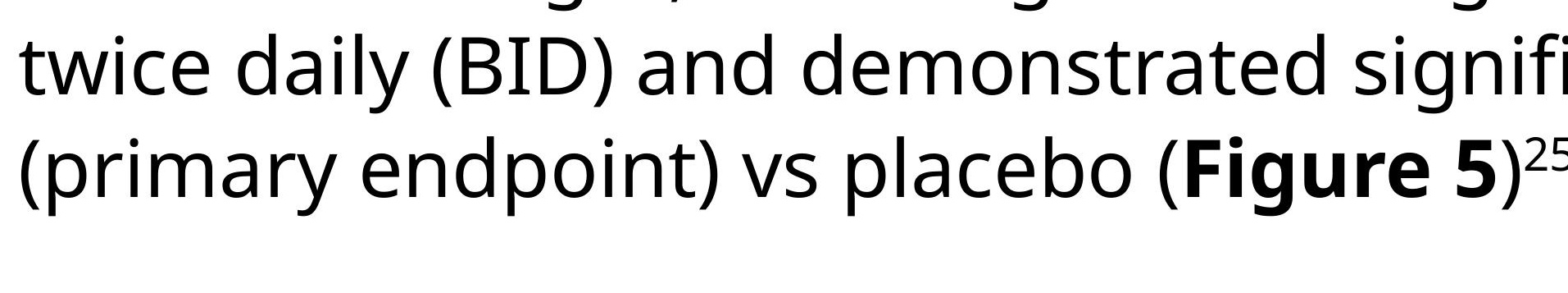

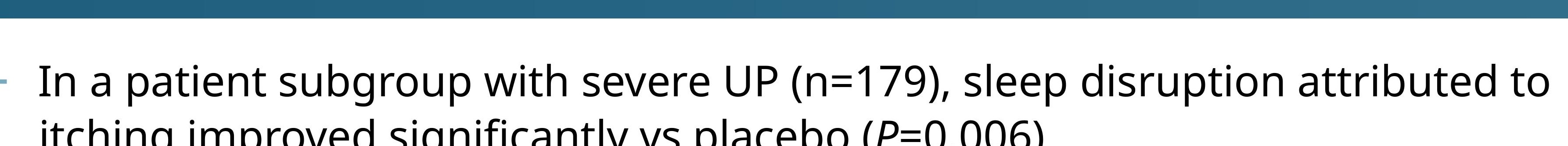
The most common reason for discontinuing tree
effects

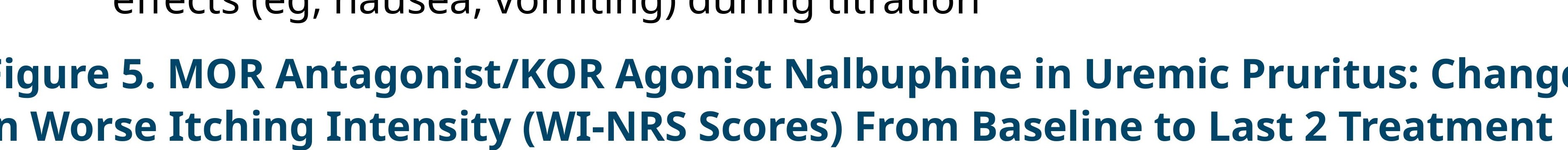

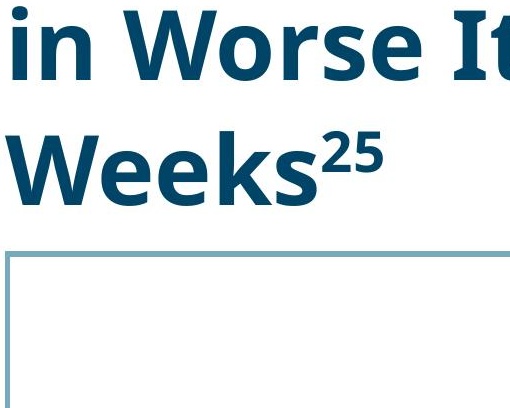

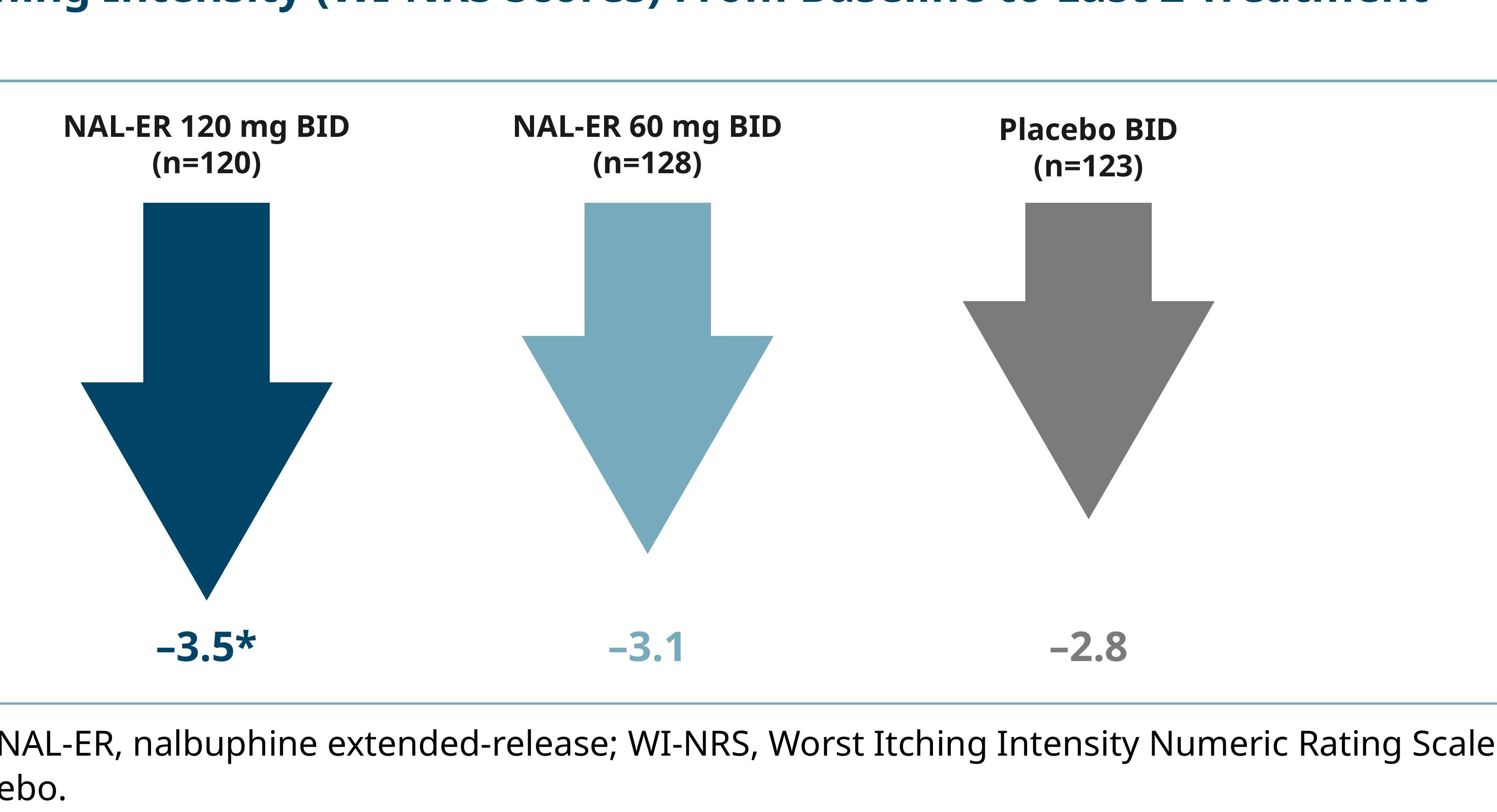

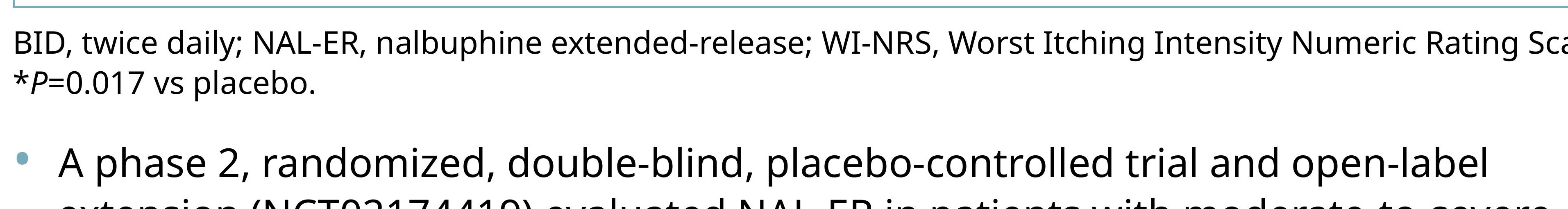

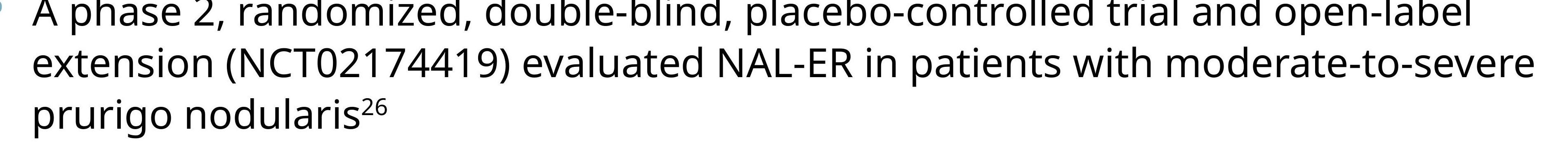

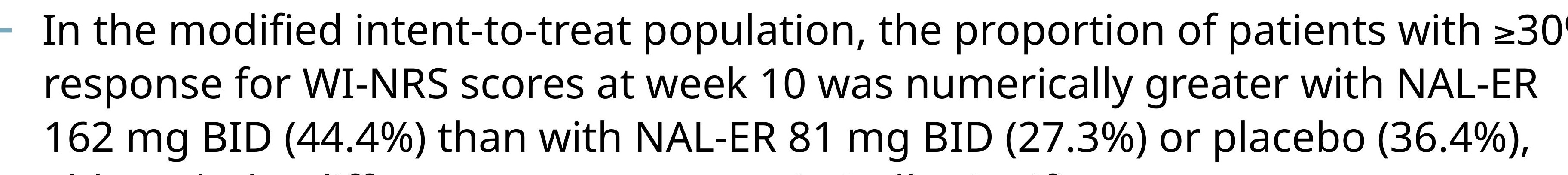

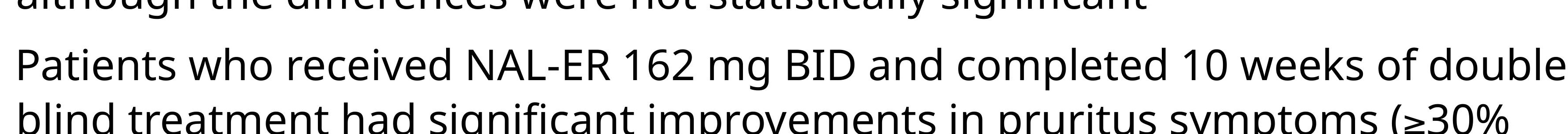

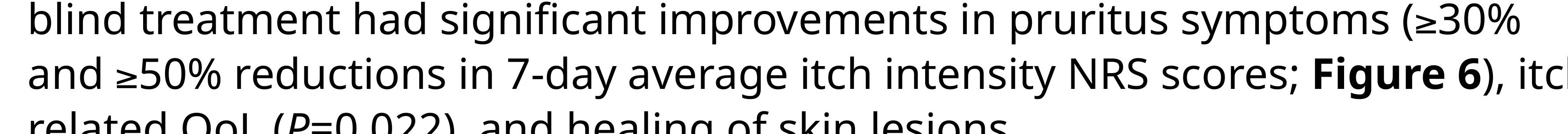

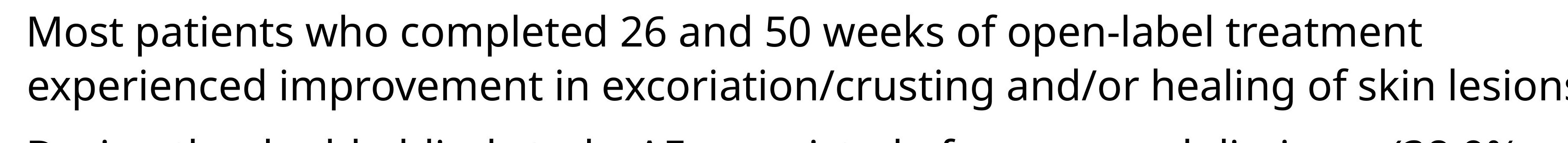

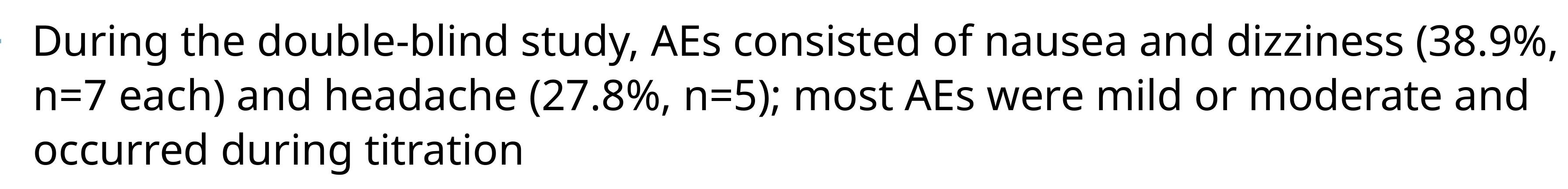

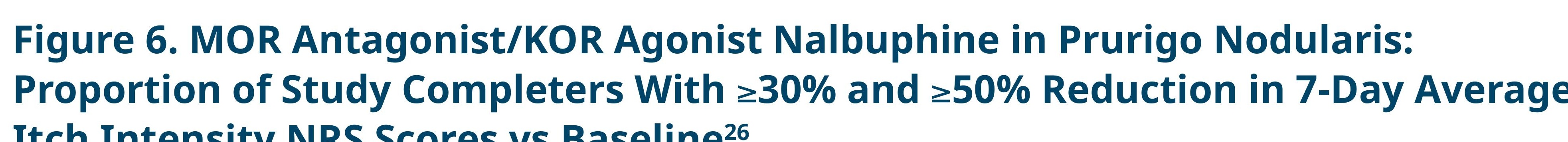

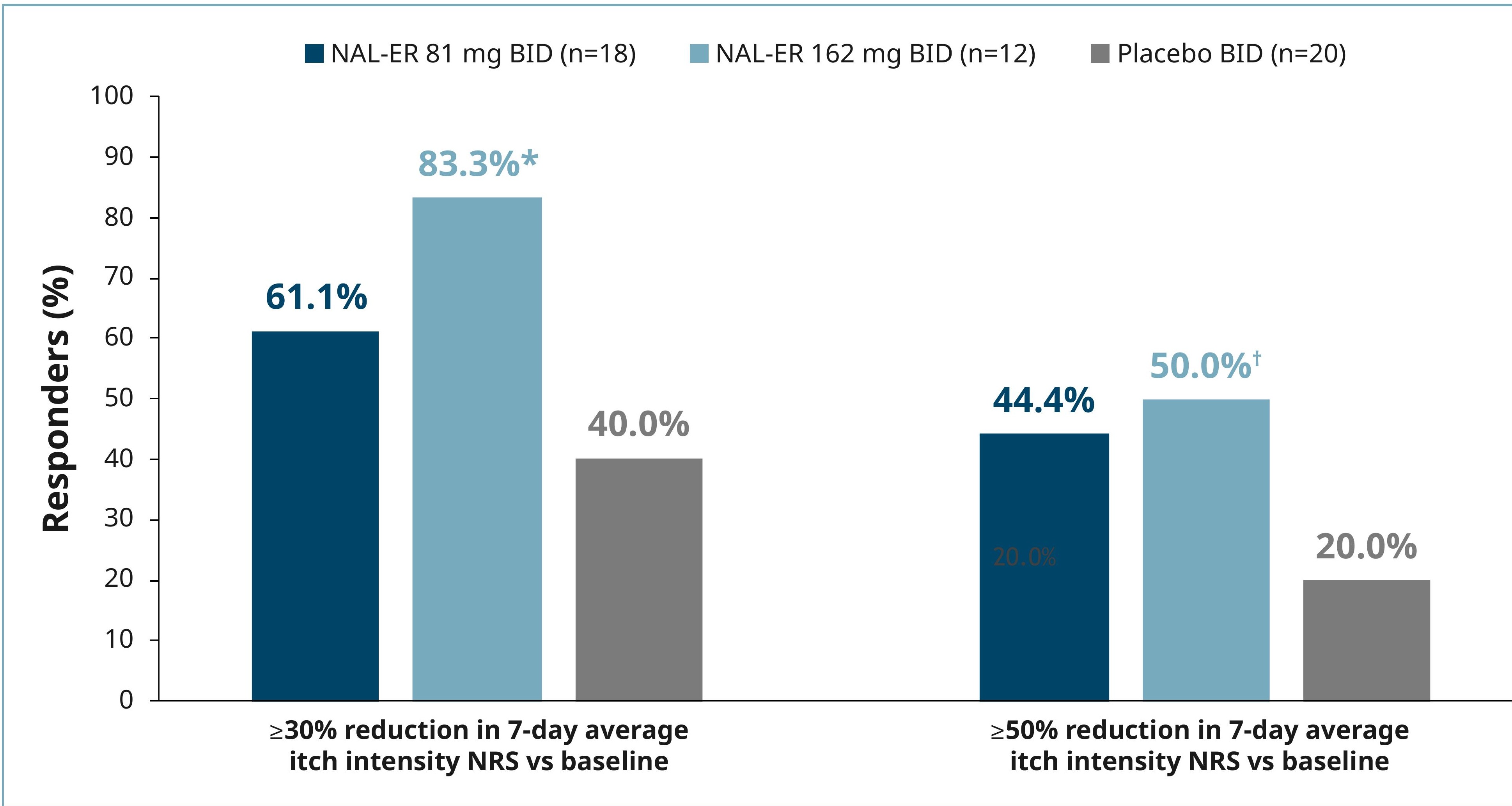

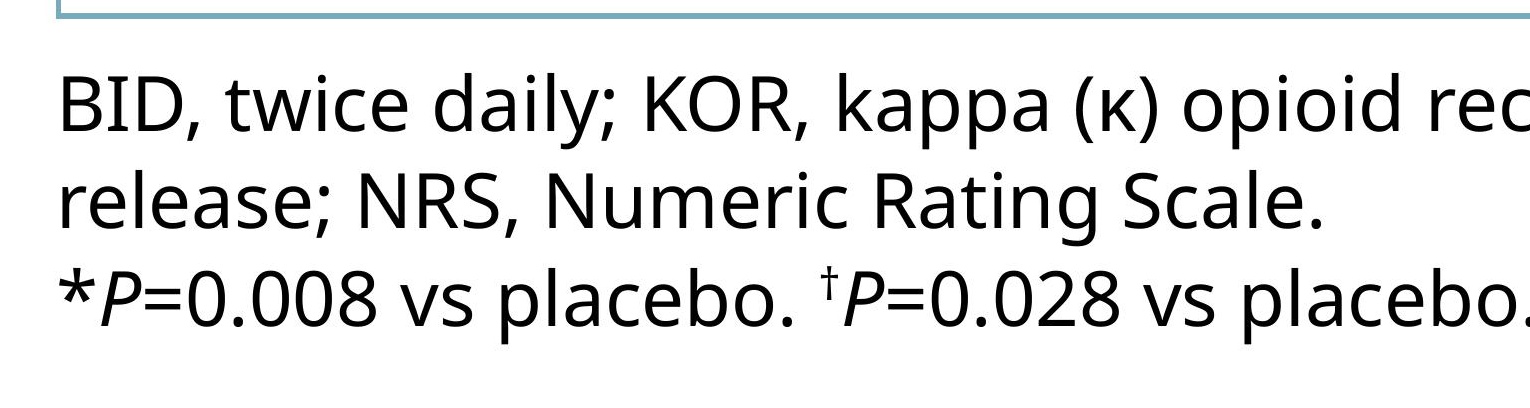

\section{Conclusions}

These data suggest that agents that modulate underlying
neurologicic commonents and/or $k$-agonism are effective and safe options for the
treatment

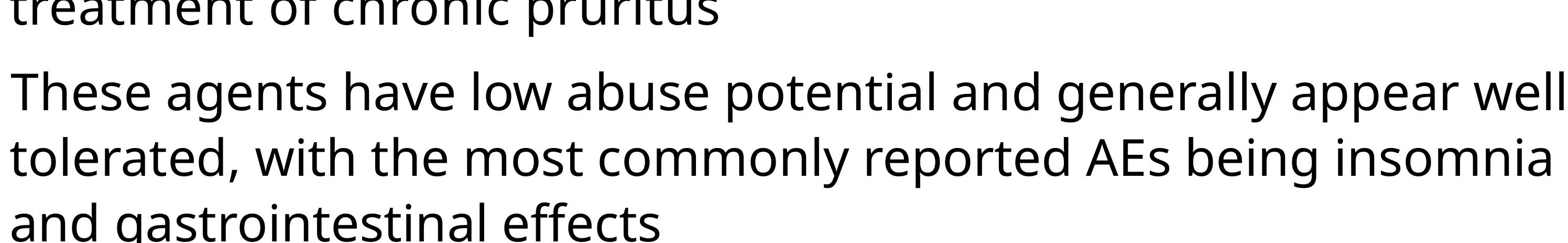

Disclosures

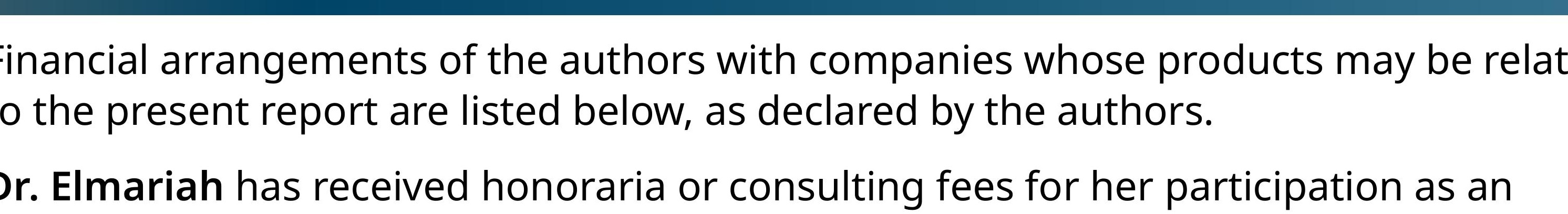

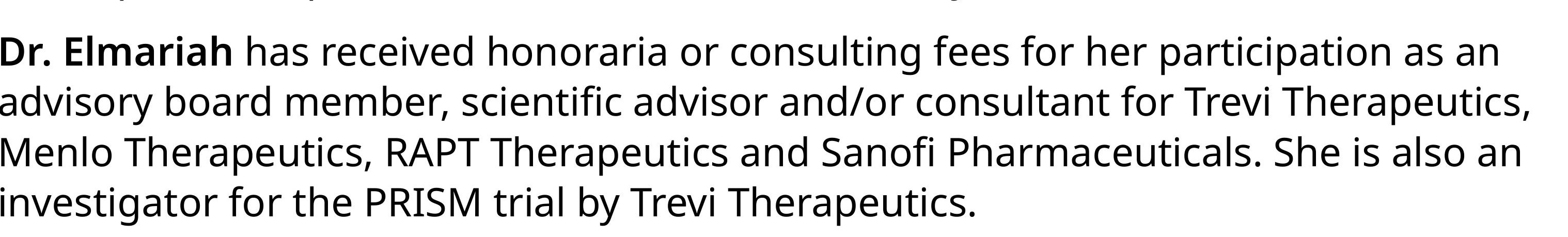

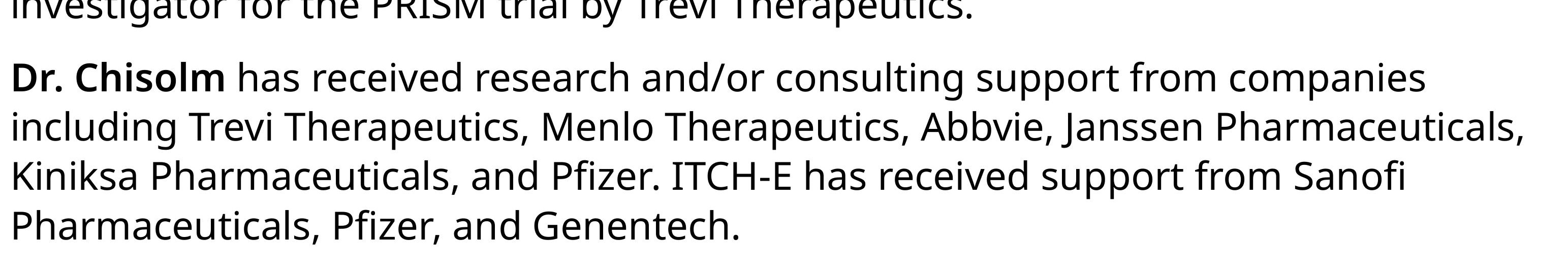

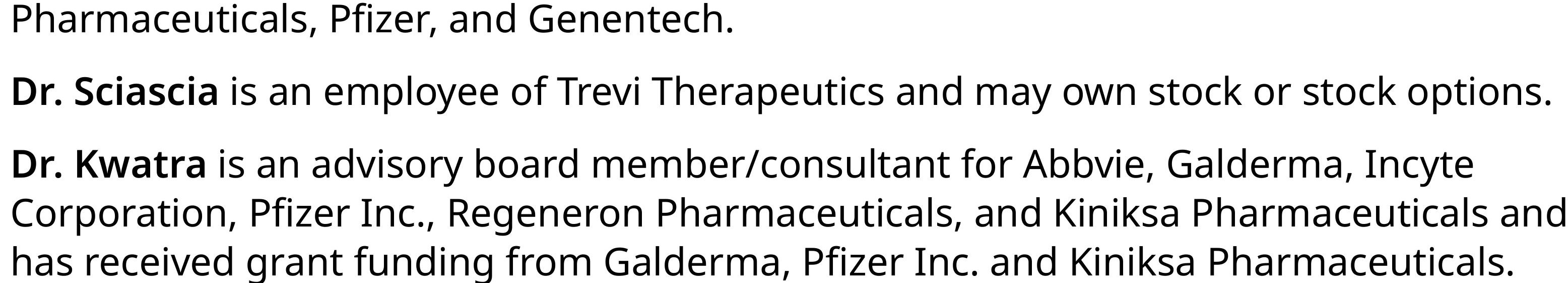

\section{Acknowledgments}

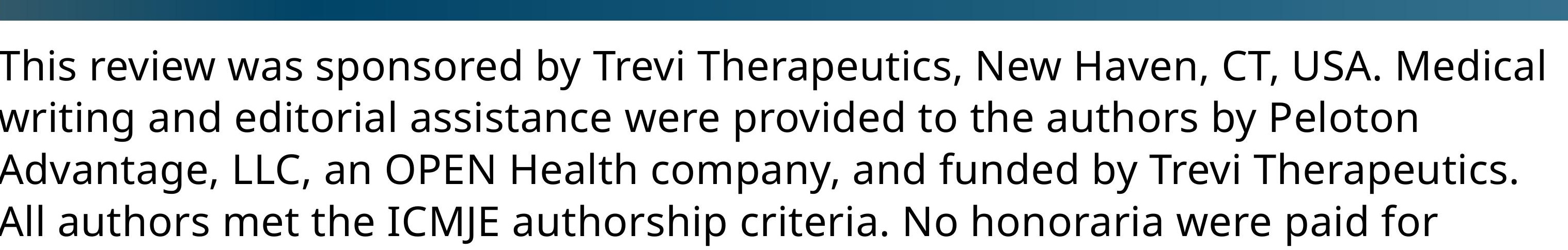

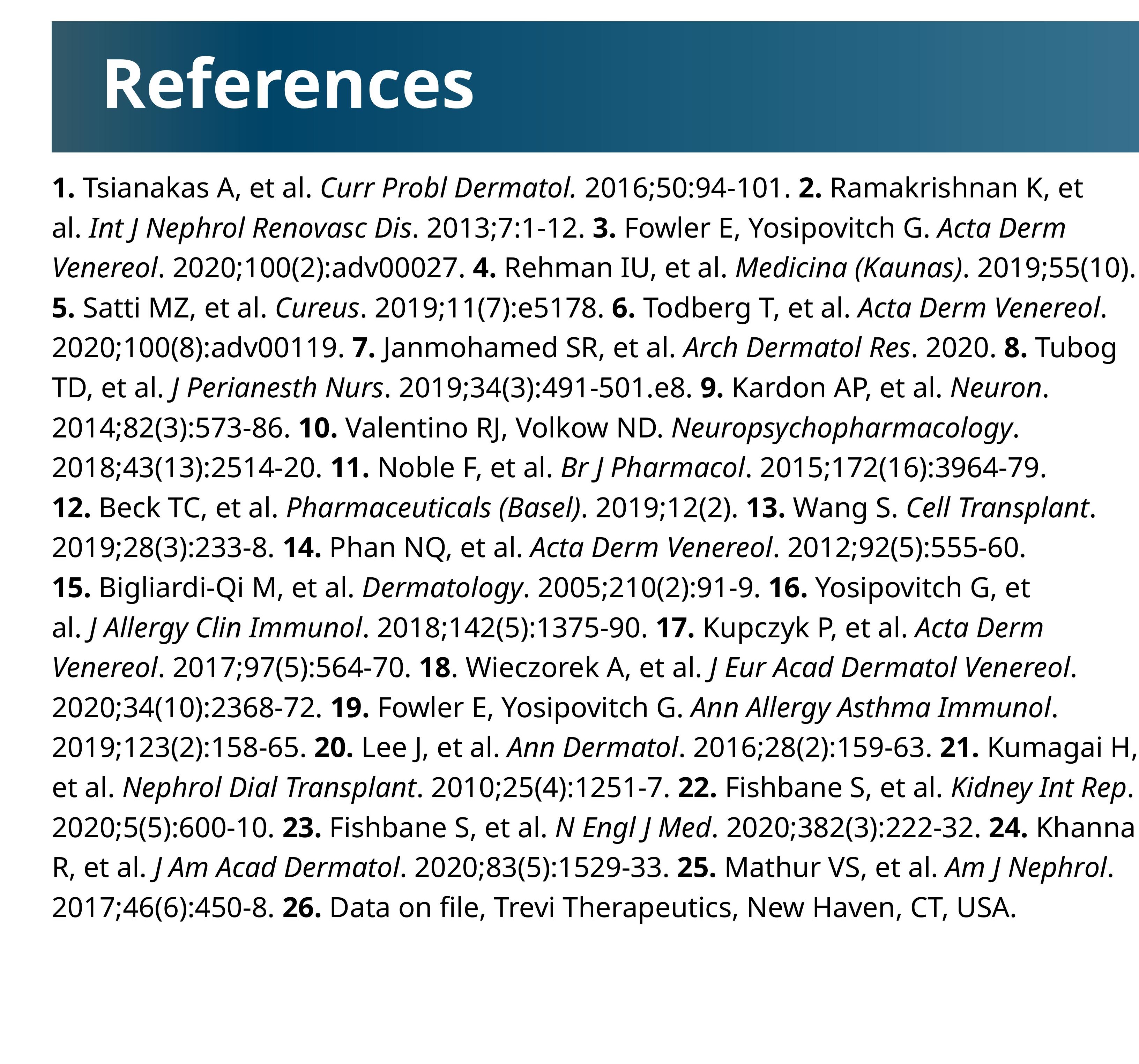

